Part of Journal of Research of the National Bureau of Standards, Volume 16, March 1936

\title{
DISTILLATION AND SEPARATION OF ARSENIC, ANTIMONY, AND TIN
}

\author{
By John A. Scherrer
}

ABSTRACT

This paper describes an apparatus and the technique for the separation, by distillation, of arsenic, antimony, and tin from one another and from elements having nonvolatile chlorides. The apparatus is made entirely of glass, for it was found that cork and rubber stoppers absorb the vapors to such an extent that significant errors may ensue.

CONTENTS

I. Introduction

II. Principles involved

III. Description of the apparatus

IV. Directions for using the apparatus

1. Preparation of the solution 255

2. Distillation of arsenic

3. Distillation of antimony 256

4. Distillation of tin

V. Determination of arsenic, antimony, and tin, and qualitative tests_- $\quad 257$

VI. Results obtained.

VII. Discussion of the method

1. Apparatus. 259

2. Method

3. Volatility of other chlorides

\section{INTRODUCTION}

In chemical analysis it is often desirable to separate arsenic, antimony, and tin from one another and from elements having nonvolatile chlorides before determinations are attempted. This is particularly true if they occur in very small amounts, for then it is comforting to have visual evidence of their presence. Many ores and alloys contain at least two and often all three of these elements.

The separation and determination of arsenic by volatilization was first employed by Emil Fischer. ${ }^{1}$ Various methods for the distillation of these elements from solutions containing halogen acids have been published. W. Plato ${ }^{2}$ and W. Hartmann ${ }^{3}$ recommend the distillation of the arsenic and antimony together, and then the tin, each distillation being made under special conditions. The arsenic is then removed from the strong acid distillate by hydrogen sulphide, and then the antimony from the partially neutralized filtrate.

K. K. Järvinen ${ }^{4}$ recommends that arsenic be distilled by the use of a dephlegmator, leaving the antimony and tin in the residue. The three elements are then determined volumetrically.

\footnotetext{
1 Ber. deut. chem. Ges. 13, 1778 (1880); Liebig's Ann. 208, 182 (1881); Z. anal. Chem. 21, 266 (1882).

2 Z. anorg. allgem. Chem. 68, 26 (1910).

3 Z. anal. Chem. 58, 148 (1919).

Z. anal. Chem. 62, 192 (1923).
} 
Heinrich Biltz ${ }^{5}$ uses a combination of the above methods and distills each element separately, and then determines them by suitable methods. In the usual case distillations are made in flasks carrying cork or rubber stoppers.

In attempting to determine very small amounts of antimony in irons and steels, it was found that while arsenic, antimony, and tin could be separated sharply by distillation, the use of rubber stoppers led to significant errors. These were not only more or less attacked during distillations but also absorbed the volatilized compounds. The latter are not permanently fixed, and much of what is absorbed in one run may be given off in the next. In order to overcome these difficulties, the distilling apparatus was constructed entirely of glass. After the preliminary tests with antimony, it was decided to extend the work to the quantitiative separations of arsenic and tin as well, and to cover large as well as small amounts of all three elements.

\section{PRINCIPLES INVOLVED}

Arsenic trichloride boils at $130^{\circ} \mathrm{C}$; antimony trichloride at $220.2^{\circ}$ $\mathrm{C}$; and stannic chloride at $114^{\circ} \mathrm{C}$. Ársenic distills very readily when it is present as the trivalent chloride and the hydrochloric acid is rather concentrated. Ordinarily the temperature of the boiling solution does not exceed $112^{\circ} \mathrm{C}$. There is very little danger of antimony being carried over with the arsenic, although a few tenths of a milligram may be found in the arsenic trichloride distillate if the concentration of antimony trichloride is high.

In order to bring about rapid distillation of the antimony, it is necessary to raise the temperature to about $160^{\circ} \mathrm{C}$, and to add acid, drop by drop, through a tube reaching to the bottom of the distilling flask. If the hydrochloric acid is dropped on the surface of the hot solution, much of the hydrochloric acid gas escapes without coming into intimate contact with the solution of the antimony salts and the distillation is less efficient. Tin is prevented from volatilizing with the antimony at this stage by adding phosphoric acid, with which it forms a stable compound.

Finally, the stable nonvolatile compound which phosphoric acid forms with the tin salt is broken up by the addition of hydrobromic acid, and tin is distilled with a mixture of hydrobromic and hydrochloric acids at $140^{\circ} \mathrm{C}$.

The temperature at which the distillations of the antimony and tin were made are those recommended by Heinrich Biltz. ${ }^{6}$

\section{DESCRIPTION OF THE APPARATUS}

In figure $1, \mathrm{~A}$ is a $50-\mathrm{ml}$ bulb for holding the acid which is added in the course of the distillations. The tube connecting $\mathrm{A}$ and $\mathrm{B}$, and extending into $\mathrm{B}$, is made about $25 \mathrm{~cm}$ in length, in order to overcome the pressure of the carbon dioxide which is used to aid in carrying

s Z. anal. Chem. 81, 82 (1930).

6 See footnote 5 . 
over the vapors from the distilling flask $\mathrm{C}$. The part of this tube extending into B should have a diameter of not over 3 to $4 \mathrm{~mm}$ in order to prevent the acid from draining from it.

$\mathrm{B}$ is an arrangement for gaging the rate of flow of the acid, and is provided with a side tube for the purpose of introducing a stream of carbon dioxide.

$\mathrm{C}$ is a $200-\mathrm{ml}$ distilling flask, the neck of which is $2.5 \mathrm{~cm}$ in diameter. It is provided with a side tube, a thermometer well, and a delivery tube for conveying the acids and carbon dioxide to the distilling flask. The side tube connects the apparatus to a condenser, the thermometer well is sealed to the top of the neck of the flask, and the delivery tube passes through the wall in the upper part of the neck of the flask and is connected to B. Both the thermometer well and delivery tube reach within $3 \mathrm{~mm}$ of the bottom of the flask. The distance between the bottom of the flask and the exit tube leading to the condenser is $17 \mathrm{~cm}$.

The apparatus is clamped to a ring stand. C rests on an asbestos board (about 18 by $18 \mathrm{~cm}$ ) having a round hole $4.5 \mathrm{~cm}$ in diameter.

It is desirable that all the glass should be free from the elements in question, and the suitability of the setup for the work in hand should be determined by running appropriate blanks.

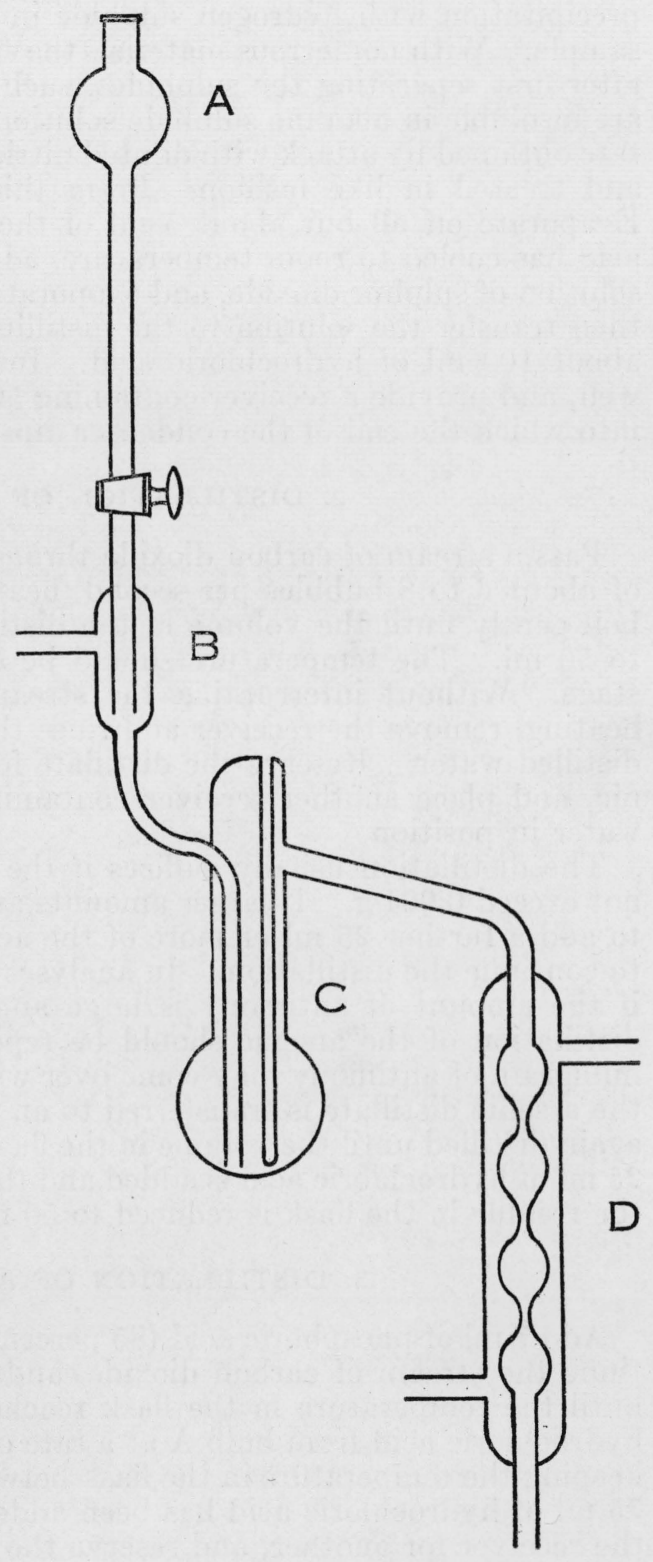

Figure 1.-Distilling apparatus.

\section{DIRECTIONS FOR USING THE APPARATUS}

\section{PREPARATION OF THE SOLUTION}

In the usual case arsenic, antimony, and tin are first precipitated as the sulphides and then converted to sulphates by treating paper 
and precipitate with nitric and sulphuric acids, ${ }^{7}$ finally heating until copious fumes of sulphuric acid are given off. With ferrous materials, such as irons and steels, the sulphides can be obtained by direct precipitation with hydrogen sulphide in a nitric acid solution of the sample. ${ }^{8}$ With nonferrous materials the sulphides are usually obtained after first separating the sulphides, such as copper and lead, which are insoluble in alkaline sulphide solution. With solders the precipitate obtained by attack with diluted nitric acid $(1+2)$ can be gathered and treated in like fashion. From this point proceed as follows: Evaporate off all but about $5 \mathrm{ml}$ of the sulphuric acid. When the acid has cooled to room temperature, add 30 to $50 \mathrm{ml}$ of a saturated solution of sulphur dioxide, and evaporate to about $10 \mathrm{ml}$. Cool, and then transfer the solution to the distilling apparatus with the aid of about $100 \mathrm{ml}$ of hydrochloric acid. Insert the thermometer in the well, and provide a receiver containing 50 to $100 \mathrm{ml}$ of distilled water into which the end of the condenser dips.

\section{DISTILLATION OF ARSENIC}

Pass a stream of carbon dioxide through the apparatus at the rate of about 6 to 8 bubbles per second, heat the solution to boiling and boil gently until the volume in the distilling flask has been reduced to $50 \mathrm{ml}$. The temperature should be about 111 to $112^{\circ} \mathrm{C}$ at this stage. Without interrupting the stream of carbon dioxide or the heating, remove the receiver and rinse the end of the condenser with distilled water. Reserve the distillate for the determination of arsenic, and place another receiver containing 50 to $100 \mathrm{ml}$ of distilled water in position.

The distillation usually suffices if the amount of the arsenic does not exceed $0.001 \mathrm{~g}$. If larger amounts are in question, it is advisable to add a further $25 \mathrm{ml}$ or more of the acid to the distilling flask and to continue the distillation. In analyses of the highest accuracy, and if the amount of antimony is large and of arsenic very small, the distillation of the arsenic should be repeated, for a few tenths of a milligram of antimony may come over with the arsenic. In this case the arsenic distillate is transferred to an empty distillation flask, and again distilled until the volume in the flask is reduced to $50 \mathrm{ml}$. Then $25 \mathrm{ml}$ of hydrochloric acid is added and the distillation continued until the residue in the flask is reduced to $50 \mathrm{ml}$.

\section{DISTILLATION OF ANTIMONY}

Add $7 \mathrm{ml}$ of phosphoric acid (85 percent) to the distilling flask, continue the stream of carbon dioxide, and increase the heat gradually until the temperature in the flask reaches $155^{\circ} \mathrm{C}$. Then introduce hydrochloric acid from bulb $\mathrm{A}$ at a rate of 30 to 40 drops per minute, keeping the temperature in the flask between 155 and $165^{\circ} \mathrm{C}$. When $75 \mathrm{ml}$ of hydrochloric acid has been added, turn off the heat, change the receiver for another, and reserve the distillate for the determination of antimony. If the amount of antimony does not exceed about $0.001 \mathrm{~g}$, the above amount of acid suffices. With larger amounts of

7 Throughout this paper, whenever acids are mentioned, hydrochloric acid will mean the concentrated acid of specific gravity 1.18; hydrobromic acid, the concentrated acid of 40 percent; nitric acid, the concentrated acid of specific gravity 1.42 ; and sulphuric acid, the concentrated acid of specific gravity 1.84 ; diluted acids will be designated as follows: For example, diluted hydrochloric acid $(1+99)$ will mean one volume of the concentrated acid of specific gravity 1.18 diluted with 99 parts of water.

8 J. A. Scherrer, BS J. Research 8, 309 (1932) RP415. 
antimony a further $25 \mathrm{ml}$ or more of the acid should be added to bulb $\mathrm{A}$ and the distillation continued.

\section{DISTILLATION OF TIN}

Allow the solution in $\mathrm{C}$ to cool to $140^{\circ} \mathrm{C}$, turn on the heat, add a mixture of three-fourths hydrochloric acid and one-fourth hydrobromic acid to bulb A. Allow it to flow into the distilling flask at a rate of 30 to 40 drops per minute as in the distillation of antimony, keeping the temperature at about $140^{\circ} \mathrm{C}$. When $50 \mathrm{ml}$ of the mixed acids has been added, remove the source of heat, interrupt the stream of carbon dioxide, and reserve the distillate for the determination of tin. If the amount of tin does not exceed $0.001 \mathrm{~g}$, the above amount of acid is sufficient. If more is present, a further $25 \mathrm{ml}$ or more of the mixed acids should be added to bulb $\mathrm{A}$, and the distillation continued.

\section{DETERMINATION OF ARSENIC, ANTIMONY, AND TIN, AND QUALITATIVE TESTS}

The elements in the distillates were determined as follows:

Arsenic.-The cold distillate was neutralized with sodium hydroxide, made slightly acid with hydrochloric acid, and cooled to room temperature. The acid was neutralized with sodium bicarbonate, and then an excess of $20 \mathrm{ml}$ of a saturated solution of sodium bicarbonate was added. The arsenic was then titrated with a standard solution of iodine, using a solution of starch as indicator. A careful blank run was made on the same amounts of reagents as were used with the sample, and the proper correction applied.

Antimony.-The distillate was neutralized with ammonium hydroxide, after which $5 \mathrm{ml}$ of hydrochloric acid was added for each $100 \mathrm{ml}$ of solution. Hydrogen sulphide was then passed through the solution for about 15 minutes. After standing for 30 minutes the solution was filtered and the precipitate washed 6 to 8 times with a solution of diluted sulphuric $(3+97)$ acid which was saturated with hydrogen sulphide. The paper and precipitate were transferred to a kjeldahl flask and treated with $10 \mathrm{ml}$ of sulphuric acid and $5 \mathrm{~g}$ of potassium or sodium sulphate. The contents of the flask were gradually heated to boiling and the boiling continued until the organic matter was completely destroyed. When cool, $250 \mathrm{ml}$ of distilled water and $25 \mathrm{ml}$ of hydrochloric acid were added, the solution was boiled for a few minutes, cooled to $10^{\circ} \mathrm{C}$ and titrated with a $0.1 \mathrm{~N}$ solution of potassium permanganate.

Tin.-The distillate was transferred to an erlenmeyer flask and water added until the solution contained 25 to 30 percent of hydrochloric and hydrobromic acids (by volume). The tin was reduced by boiling with an excess of test lead for about 30 minutes. The solution was then cooled to $10^{\circ} \mathrm{C}$ and titrated with $0.1 \mathrm{~N}$ solution of iodine using a starch solution as indicator. A stream of carbon dioxide was passed through the apparatus during the reduction, cooling, and titration.

Qualitative tests.-If the amounts of the elements are very small, it is desirable in every case to treat the distillates with hydrogen sulphide after proper neutralization in order to have visual proof that they are present. After appropriate digestion the solution is then filtered, of course, and the sulfides treated as may be desired. 


\section{RESULTS OBTAINED}

The procedure was first tested qualitatively by using a synthetic solution which contained $50 \mathrm{ml}$ of hydrochloric acid and the maximum amounts of the elements that might be expected in $25 \mathrm{~g}$ of ordinary irons and steels. The amounts taken were arsenic $6 \mathrm{mg}$, antimony $3 \mathrm{mg}$, and tin $6 \mathrm{mg}$. The arsenic was distilled by adding $60 \mathrm{ml}$ of hydrochloric acid in the course of 60 minutes, antimony by using $75 \mathrm{ml}$ of hydrochloric acid in the course of 70 minutes, and tin by using $45 \mathrm{ml}$ of hydrochloric acid and $15 \mathrm{ml}$ of hydrobromic acid in the course of 45 minutes. The completeness of the distillation of each element was tested by changing the receiver, adding $25 \mathrm{ml}$ more of the acid or acids, and repeating the distillation. The new distillate was treated with hydrogen sulphide after adjusting the acidity. In all cases no more of the element was obtained in the additional distillation.

TABLE 1.-Results obtained in distillations of arsenic, antimony, and tin

\begin{tabular}{|c|c|c|c|c|c|c|}
\hline \multirow{2}{*}{ Test } & \multicolumn{2}{|c|}{ Arsenic } & \multicolumn{2}{|c|}{ Antimony } & \multicolumn{2}{|c|}{ Tin } \\
\hline & Taken & Found & Taken & Found & Taken & Found \\
\hline 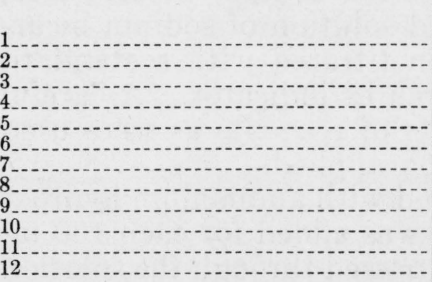 & $\begin{array}{c}\mathrm{g} \\
0.0100 \\
\text { None } \\
\text { None } \\
\text { None } \\
.1000 \\
.1000 \\
\text { None } \\
.1000 \\
.0001 \\
.0001 \\
.1000 \\
.1000\end{array}$ & $\begin{array}{l}\mathrm{g} \\
0.0098 \\
\text { (a) } \\
\text { (a) } \\
\text { (a) } \\
.1000 \\
.1002 \\
\text { (a) } \\
.0998 \\
\text { (b) } \\
\text { (b) } \\
.0999 \\
.0998\end{array}$ & $\begin{array}{c}\mathrm{g} \\
0.0100 \\
.0100 \\
\text { None } \\
.1000 \\
\text { None } \\
.1000 \\
\text { None } \\
.1000 \\
.0001 \\
.1000 \\
.0001 \\
.1000\end{array}$ & $\begin{array}{l}\mathrm{g} \\
0.0103 \\
.0099 \\
\text { (a) } \\
.1003 \\
\text { (a) } \\
\text {.1001 } \\
\text { (a) } \\
.0998 \\
\text { (b) } \\
.0999 \\
\text { (b) } \\
.0999\end{array}$ & $\begin{array}{c}\mathrm{g} \\
0.0100 \\
.0100 \\
.0100 \\
.1000 \\
\text { None } \\
\text { None } \\
.1000 \\
.1000 \\
.0001 \\
.1000 \\
.1000 \\
.0001\end{array}$ & $\begin{array}{l}\mathrm{g} \\
0.0103 \\
.0101 \\
.0102 \\
.1001 \\
\text { (a) } \\
\text { (a) } \\
.0999 \\
.1003 \\
\text { (b) } \\
.1000 \\
.0998 \\
\text { (b) }\end{array}$ \\
\hline
\end{tabular}

a No precipitate was obtained by treating the properly neutralized distillate with hydrogen sulphide, and digesting for several hours.

b Qualitative tests for the element in question were obtained.

Tests 1 to 3 in table 1 were obtained as in the preliminary qualitative test, except that $75 \mathrm{ml}$ of hydrochloric acid was added for arsenic and the distillation completed in 60 minutes, $85 \mathrm{ml}$ of hydrochloric acid added for antimony and completed in 50 minutes from the time that the addition of acid began, and $75 \mathrm{ml}$ of a mixture of three-fourths hydrochloric and one-fourth hydrobromic acids added for tin and completed in about 45 minutes.

Tests 4 to 12 were obtained by distilling mixtures containing relatively large amounts of the three elements. The amounts of acids used and the distillates caught were somewhat in excess of the amounts specified in the procedure, in view of the amounts of the elements that were present. In the distillation of arsenic approximately $100 \mathrm{ml}$ of distillate was gathered in the course of 90 minutes, in the distillation of antimony approximately $150 \mathrm{ml}$ of the distillate was gathered in the course of 90 minutes from the time that the addition of the acid began, and in the case of tin, $120 \mathrm{ml}$ of distillate was gathered in the course of 60 minutes. 


\section{DISCUSSION OF THE METHOD}

\section{APPARATUS}

The separate parts of the apparatus may be made with ground joints, but experience has shown that the joints may stick when used at elevated temperatures. The one-piece apparatus proved to be rugged and easily cleaned by pouring acids through $\mathrm{A}$ and rinsing the solutions through the condenser.

The distance from the bottom of the distilling flask to the exit tube has been found in practice to be satisfactory.

The thermometer well probably causes a slight lag in the temperature, but in view of the wide range over which the temperature may vary it is of no consequence. The well is placed in front of the exit tube so that it acts as a baffle to prevent spray from passing into the condenser.

\section{METHOD}

The carbon dioxide has the double purpose of aiding in carrying over the volatile compounds and to prevent bumping.

According to Heinrich Biltz, ${ }^{9}$ when one arsenic distillation follows another the apparatus should be rinsed with hydrochloric acid between distillations, for if antimony is present it has a tendency to creep along the surface of the flask, and unless removed will finally pass over to some extent.

\section{VOLATILITY OF OTHER CHLORIDES}

Germanium.-100 $\mathrm{mg}$ of germanium as the tetrachloride was distilled under the conditions that obtain in the arsenic distillation. All of the germanium was found in the distillate.

Bismuth. $-100 \mathrm{mg}$ of bismuth as the trichloride was placed in the apparatus and the distillation carried out as for arsenic, antimony, and tin. No bismuth was found in any of the three distillates.

Rhenium.-When $100 \mathrm{mg}$ of rhenium as the perrhenate was introduced under conditions that obtain for arsenic, antimony, and tin, no rhenium was found in the arsenic distillate, about $50 \mathrm{mg}$ in the antimony distillate, about $25 \mathrm{mg}$ in the tin distillate, and $25 \mathrm{mg}$ in the residue.

Molybdenum.-When $100 \mathrm{mg}$ of molybdenum was introduced as molybdic acid, the arsenic distillate contained no molybdenum. About $0.2 \mathrm{mg}$ was found in the antimony distillate and about 0.3 $\mathrm{mg}$ in the tin distillate, by the thiocyanate test. When the second distillate was redistilled as for antimony, no molybdenum was found in the fraction which distilled over, the molybdenum being found in the residue. The tin distillate was concentrated in the apparatus and redistilled in the presence of the mixed acids as for tin. The fraction which passed over contained about $0.01 \mathrm{mg}$ of molybdenum, the residue the rest. In very careful work a third distillation should be made.

Washington, February 3, 1936.

See footnote 5 .

$49283-36-4$ 